A N N A L E S Annales de Bretagne et des Pays de l'Ouest

\title{
Benoît HABERBUSCH, La gendarmerie en Deux-Sèvres sous l'Occupation
}

\section{Marc Bergere}

\section{(2) OpenEdition}

\section{Journals}

Édition électronique

URL : http://journals.openedition.org/abpo/307

DOI : 10.4000/abpo.307

ISBN : 978-2-7535-1511-6

ISSN : 2108-6443

Éditeur

Presses universitaires de Rennes

Édition imprimée

Date de publication : 30 septembre 2008

Pagination : 204-205

ISBN : 978-2-7535-0772-2

ISSN : 0399-0826

Référence électronique

Marc Bergere, "Benoît Haberbusch, La gendarmerie en Deux-Sèvres sous l'Occupation », Annales de Bretagne et des Pays de l'Ouest [En ligne], 115-3 | 2008, mis en ligne le 30 septembre 2008, consulté le 23 septembre 2020. URL : http://journals.openedition.org/abpo/307 ; DOI : https://doi.org/10.4000/ abpo.307

Ce document a été généré automatiquement le 23 septembre 2020

(c) Presses universitaires de Rennes 


\title{
Benoît HABERBUSCH, La gendarmerie en Deux-Sèvres sous l'Occupation
}

\author{
Marc Bergere
}

\section{RÉFÉRENCE}

La Crèche, Geste éditions/histoire, 2007, 375 p.

1 Docteur en histoire, Benoît Haberbusch a soutenu en 2003 (professeur J.-N. Luc [dir.]) à l'université Paris 4-Sorbonne, une thèse consacrée à la Gendarmerie en Algérie entre 1939-1945 (publiée par le Service historique de la Gendarmerie nationale, collection études, 2004 avec une préface de Jacques Frémeaux). Cette dernière représente d'ailleurs un réel apport à la connaissance historique de la période tant sous l'angle de l'histoire de l'Arme que sous celui de la société coloniale aux prises avec les événements de la guerre (défaite, Vichy, débarquement Anglo-américain, CFLN, épuration, répression des émeutes du Constantinois en mai 1945...). Chercheur depuis de nombreuses années au sein du département gendarmerie du SHD et à ce titre co-auteur de nombreuses publications (en particulier du remarquable, Histoire de la maréchaussée et de la gendarmerie. Guide de recherche, Jean-Noël Luc (dir), Maisons-Alfort, Service historique de la gendarmerie nationale, 2005), mais aussi fils de gendarme, Benoît Haberbusch est d'abord un authentique historien qui sait éviter les pièges d'une égohistoire longtemps prédominante dans l'histoire de la gendarmerie. Il incarne d'ailleurs parfaitement la génération de jeunes chercheurs qui a profondément renouvelé l'historiographie de la gendarmerie nationale sur la décennie écoulée. Il nous livre ici une version profondément remaniée et actualisée de son mémoire de maîtrise soutenu en 1997 à l'université de Poitiers (Paul Lévy dir.). Disons-le tout de suite, cette monographie pionnière est utile tant pour la connaissance de l'institution gendarmique que pour l'analyse de la société française sous l'Occupation, au sein d'un département plutôt "tranquille ", de l'aveu même de l'auteur, mais dont précisément le caractère remarquable réside dans cette dimension ordinaire. 
2 En effet, militaires disséminés au cœur de la population civile (chapitre 1) en vertu d'un maillage serré du territoire, les gendarmes constituent un corps particulier et un objet d'étude original. Disposant d'une identité mixte (mi-civile/mi-militaire), la gendarmerie nationale par ses missions et son implantation est un observatoire privilégié des sociétés, en temps de guerre comme en temps de paix, au front comme à l'arrière, en métropole comme hors des frontières. Dès lors, appuyé sur un corpus d'archives très solide puisé aux meilleures sources (archives départementales, archives nationales, SHD-DGN mais aussi sources orales avec une vingtaine de témoignages), le livre nous donne à voir toute l'ambivalence d'un corps confronté à une conjoncture extraordinaire de la mobilisation de 1939 (chapitre 2) à la sortie de guerre via un délicat processus d'épuration (où les mesures "officieuses" ont souvent primé sur les sanctions officielles, ici plutôt limitées, chapitre 9), en passant par l'Occupation (chapitre 3), Vichy (chapitre 4) et des missions de plus en plus difficiles à assurer (exclusion des juifs, garde des camps d'internement des départements voisins, contrôle du STO, chapitres 6 et 7). En effet, instrumentalisée par Vichy et donc indirectement par les Allemands, la gendarmerie a été, sous l'occupation, détournée de ses missions traditionnelles inscrivant de plus en plus son action dans une logique d'exception, de répression et de persécution. Comparativement au reste de la société, force est de reconnaître que les gendarmes ont été davantage confrontés à des choix professionnels difficiles à assumer. On y relève pas moins, face à l'occupant et à Vichy, la même diversité de comportements et d'itinéraires que dans l'opinion médiane française (y compris Résistance, chapitre 8). Mais, plus que dans n'importe quelle autre institution, il faut ici compter sur un esprit de corps particulier dont la pierre angulaire est le devoir d'obéissance. Ce faisant, c'est aussi à une histoire d'une compagnie de gendarmerie au quotidien et parfois même "au ras des rutabagas » (chapitre 5) que l'auteur nous invite. L'ensemble justifiait pleinement une publication.

\section{AUTEURS}

MARC BERGERE 